\title{
Hemp seed oil: Chemical characterization of three non-drug varieties cultivated in Morocco
}

\author{
Taoufik Bouayoun ${ }^{1}$, Hamid Stambouli ${ }^{1}$, Yassine Ez zoubi ${ }^{2 *}$, Aziz El Bouri ${ }^{1}$, Abdellah Farah ${ }^{2}$, Mohamed Tabyaoui ${ }^{3}$ \\ ${ }^{1}$ Institutede Criminalistique de la Gendarmerie Royale-ICGR, Gendarmerie Royale, BP 6597, Rabat-Instituts CP 10100 Rabat, Morocco. ${ }^{2}$ Laboratory of Applied \\ Organic Chemistry, Faculty of Sciences and Technology, Sidi Mohamed Ben Abdellah University, Po. Box 2202 - Route d'Imouzzer, Fez, Morocco. ${ }^{3}$ Laboratory \\ of Materials, Nanotechnology and Environment, Faculty of Science, University of Mohamed-V-Av. Ibn Battouta, Po. Box 1014, Agdal-Rabat, Morocco.
}

\begin{tabular}{l}
\hline ARTICLE INFO \\
\hline Article history: \\
Received on: December 09, 2017 \\
Accepted on: April 03, 2018 \\
Available online: August 01, 2018 \\
\hline
\end{tabular}

Key words:

Cannabis sativa L. oil,

Fatty acids,

Omega-6,

Omega-3.

\begin{abstract}
Cannabis sativa L. (hemp) seed oil is known for their food use, is the amount of polyunsaturated fatty acids from hemp seeds that would make these interesting products. The yield and the chemical characterization of three varieties of non-drugs hemp oil cultivated in Morocco were determined. Three varieties were used, namely, Santhica 27, Futura 75, and Epsilon 68 listed in the French and European catalogs. The chemical composition of all varieties from hemp oils was determined using gas chromatography-mass spectrometry method. The oil content of the hemp seeds ranged between $30.45 \%$ and $34.93 \%$. Among the 09 detected fatty acids, a high level of linoleic acid (omega- 6 ) was recorded between $56.71 \pm 0.1 \%$ and $57.70 \pm 0.1 \%, \alpha$-linolenic acid (omega-3) ranged from $13.66 \pm 0.04 \%$ to 14.80 $\pm 0.06 \%$, and the oleic acid ranged from $12.80 \pm 0.04 \%$ to $13.30 \pm 0.03 \%$. Moreover, palmitic, stearic, and arachidic acids contents varied between $7.32 \pm 0.02 \%$ (Futura 75) to $7.70 \pm 0.03 \%$ (Santhica 27), $2.40 \pm 0.02 \%$ (Futura 75) to $2.60 \pm 0.04 \%$ (Epsilon 68 ), and $0.9 \%$ for all varieties, respectively. These results show that the hemp seeds cultivated in Morocco could be used as a source of food, characterized by high nutritional value.
\end{abstract}

\section{INTRODUCTION}

In Morocco, the cultivation of Cannabis sativa L. concerns the drug variety of this plant, covers an area of about 120,000 ha which covers $20,000 \mathrm{~km}^{2}$ in the northern region of the country with an average production of $750 \mathrm{~kg}$ per hectare [1-3]. The report of the United Nations Office on Drugs and Crime (UNODC), published in 2016, suggests that the world's largest producer of cannabis resin continues to be Morocco, and a large amount of cannabis production has essentially exported to Europe through traffickers [4].

Despite the reduction recorded in the province of Chefchaouen, Rif region, where cannabis cultivation increased from 79,195 ha in 2004 to 40,529 ha in $2005(-46 \%)$, the northern region of Morocco, especially the center of the Rif, remains the preferred region by cannabis resin producers [5]. Since 2005, the authorities have conducted a campaign to eradicate the cultivation of cannabis, which has reduced production in the provinces of Larache, Al Hoceima, and Taounate [5,6]. A study realized by Stambouli et al. [5] about 30 samples of hemp seeds oils

\section{*Corresponding Author:}

Yassine Ez zoubi,

Laboratory of Applied Organic Chemistry,

Faculty of Sciences and Technology,

Sidi Mohamed Ben Abdellah University,

Po. Box 2202 - Route d'Imouzzer, Fez, Morocco.

Email: ezzoubiyassine@yahoo.fr collected in north region from Morocco confirms that the delta-9tetrahydrocannabinol $(\Delta-9-\mathrm{THC})$ content of approximately $6 \%$. With the same objective, the composition of $C$. sativa $\mathrm{L}$. seed oil grown in Northern of Morocco was also carried [7]. Moreover, a recent study realized by Bouayoun et al. [8] about three non-drug varieties of hemp (Epsilon 68, Santhica 27, and Futura 75) revealed that the average contents of delta-9-tetrahydrocannabinol were ranged from $0.013 \%$ to $0.035 \%$. The production of cannabis in Morocco remains illegal, which leads to judicial proceeding against farmers and transporters. In fact, the production and cultivation of the industrial varieties of cannabis in Morocco will have a great socioeconomic impact.

Industrial hemp is an annual plant selected for its low delta-9tetrahydrocannabinol content, developed from $C$. sativa $\mathrm{L}$. It has undergone a significant evolution since the 1990s, more than 51 species were developed in 2013 compared to 12 species cultivated in 1995 [9]. This is the result of legislative authorization by the majority of European countries [10].

Hemp seed oil is rich in essential fatty acids, characterized by a height quantity of unsaturated fatty acids, linoleic and $\alpha$-linolenic acids (omega- 6 and omega-3) are the unsaturated fatty acids most represented in vegetable oils of cannabis, with values between $50-70 \%$ and $15-25 \%$ of total oil, respectively [11]. Several researchers have studied the effects of hemp oils in cosmetic [12], antioxidant [13,14], lipid metabolism [15], cardiovascular health [16], immunomodulatory 
effects [17], and dermatological diseases [18]. In addition to the uses of the cannabis by ancient civilizations as sources of food and medication [19], and actually several products were developed by industries in food, cosmetic, and pharmaceutics areas.

In this sense, our study consists to analysis the chemical compositions of hemp seed oils from three non-drug varieties cultivated in Morocco.

\section{MATERIALS AND METHODS}

\subsection{Plant Material}

The hemp seeds used in this work come from the experimental plots of the cultivation of varieties of industrial hemp [8]. During this experiment, three varieties were used, namely, Santhica 27, Futura 75, and Epsilon 68 (S27, F75, and E68) listed in the French and European catalogs were received from the company "The National Federation of Hemp Producers," France. Agronomic and industrial characteristics of the industrial hemp are presented in Table 1. The major criterion adopted in breeding is to achieve very low $\Delta-9$-THC contents (see the trace). This criterion cancels the drug effect of the plant. The seeds used are from the Moroccan experimental plots.

\subsection{Morphological Characteristics of Seeds}

Microscopic examination of cannabis seeds was conducted at the Royal Gendarmerie Criminal Institute (Rabat) using an FEI Quanta 650 environmental microscope. The selected specimens are fixed on a carbon double-sided adhesive backing and to avoid any accumulation of parasitic charges which decrease the quality of the image, they are metalized in carbon before being introduced into the microscope enclosure. The observations are carried out under vacuum (7.4 10 $10^{-4}$ Pascal) at a voltage of $1-2 \mathrm{KV}$.

\subsection{Soxhlet Extraction of Oils}

About $30 \mathrm{~g}$ of hemp seeds (Santhica 27, Futura 75, and Epsilon 68) were slightly crushed and extracted by hexane using Soxhlet apparatus. Hexane was removed by a rotary evaporator and the oily portion was recovered. The oils obtained were weighed and the yields were calculated.

\subsubsection{GC Analysis of Fatty Acids}

Preparations of each sample of the fatty acid methyl esters (FAME) by transesterification of with $2 \mathrm{~N} \mathrm{KOH}$ in methanol and hexane. The gas chromatographic conditions were as follows: Capillary column CARBOWAX $20 \mathrm{M}(25 \mathrm{~m} \times 0.32 \mathrm{~mm}$ with $0.25 \mu \mathrm{m})$; The Agilent autosystem brand chromatograph is equipped with a divider injector $240^{\circ} \mathrm{C}$; detector $260^{\circ} \mathrm{C}$; nitrogen as the carrier gas; and flow rate $2.5 \mathrm{ml} / \mathrm{min}$, and the analyzes are carried out in isotherm $\left(200^{\circ} \mathrm{C}\right) .1 \mathrm{~mL}$ of each sample was injected in the splitless mode, and the determination of the fatty acids was carried out by comparing the retention times with the corresponding methyl esters of fatty acid standards. Palmitic acid (W283207), palmitoleic acid (P9417), stearic acid (W303518), oleic acid (W281506), linoleic acid (W338020), linolenic acid (L2376), arachidic acid (10930), and arachidonic acid (10931) have been used as standards, and FAME was obtained from Sigma Chemical Co. (Sigma-Aldrich, Germany).

FAME samples were analyzed and the values are presented as the mean \pm standard error of mean of triplicate analysis using one-way analysis of variance.

\section{RESULTS}

\subsection{Morphological Characteristics of Female Fruits: Seeds}

Figure 1 represents the microscopy of three varieties (Santhica 27, Futura 75, and Epsilon 68) of female hemp seeds characterized by an achene, contains a single seed with a hard shell tightly covered by the thin wall of the ovary, ellipsoid, lightly compressed, smooth, about 2-5 $\mathrm{mm}$ long, with a brown color.

\subsection{Yields of Seeds and Oils of the Three Hemp Varieties}

Oils contents of the seeds determined by Soxhlet extraction were $34.93,33.86$, and $30.45 \%(\mathrm{w} / \mathrm{w})$ of Epsilon 68, Santhica 27, and Futura 75 varieties, respectively [Table 2].

\subsection{Fatty Acid Quality of Three Varieties of Seeds Oil}

Table 3 summarizes the chemical composition of all the varieties oils. The results show that the fatty acids composition of the all varieties studied has a very close composition. The saturated fatty acids contents ( $\%$ of total oils) such as palmitic, stearic, and arachidic acids ranged from $7.32 \pm 0.02 \%$ (Futura 75 ) to $7.70 \pm 0.03 \%$ (Santhica 27), $2.40 \pm 0.02 \%$ (Futura 75 and Santhica 27) to $2.60 \pm 0.04 \%$ (Epsilon 68), and $0.9 \%$ (Futura 75, Santhica 27, and Epsilon 68), respectively. The saturated fatty acid fraction represents between $10.6 \%$ and $11 \%$ of the total fatty acids present in hemp seeds.

\section{DISCUSSION}

The values of yields obtained in this study were within the expected range reported previously for hemp seed [20,21], a study was conducted by Anwar et al. [22] proved that the yield of hemp seeds grown in Pakistan (28.87\%) was less than that found in our study. Regarding the yield of hemp seed oil, values between $35.27 \%$ and $36.88 \%$ were recorded in the northwest of Turkey [23]. The quantitative difference in the content of hemp oils could be explained by the effects of environmental factors and the storage methods [20,24,25].

Among the chemical composition, our results were similar to that of the previous studies [11,19,20,22]. Parker et al. [26] and Kriese et al. [20] were reported that stearic and palmitic acid concentrations are in accordance with our results. Several studies have shown that stearic acid does not increase the concentration of cholesterol, and oil with high concentration of stearic acid is more preferred for the food industries and in hypoglycemic diets than oils rich in palmitic acid [27-29].

Table 1: Some agronomic characteristics of varieties of industrial hemp.

\begin{tabular}{llclccc} 
Varieties & Flowering & Registration year & Breeder & THC (\%) & PMG & Fiber production (\%) \\
Santhica 27 & Average & 2002 & NFHP & $<0.001$ & 16.8 & 35.81 \\
Epsilon 68 & tardy & 1996 & NFHP & 0.04 & 19.3 & 30.45 \\
Futura 75 & tardy & 1998 & NFHP & 0.06 & 18.9 & 30.77 \\
\hline
\end{tabular}

NFHP: National Federation of Hemp Producers, PMG: Weight of thousand seeds; THC: $\Delta-9$-trans-tetrahydrocannabinol. 
In this study, the most abundant fatty acids were linoleic $(\Omega-6)$, $\alpha$-linolenic $(\Omega-3)$, and oleic acids, which together ranged between $83.6 \%$ (Santhica 27) and $87.3 \%$ (Futura 75 ) of the total fatty acid composition. A study realized by Da Porto et al. [30] have been determined a total of linoleic, $\alpha$-linolenic, and oleic acids from nondrug varieties (Felina 32, Chameleon, Uso 31, and Finola), with values between 84.93 and $88.61 \%$ of the total fatty acid composition.

Moreover, compared with the fatty acid compositions of olive and soya vegetable oils, established under the same operating conditions [Table 4 and Figure 2], proved that there is a qualitative resemblance between the three types of oils. The chromatographic profiles of the fatty acids of cannabis seed oils and soybean oil seem to have the most similarities, particularly in their oleic (between $13 \%$ and $22 \%$ ) and linoleic (between 53\% and 57\%) acid contents. However, cannabis seed oil is also characterized by a relatively high level (between $13.6 \%$

Table 2: Yields of seeds and oils of the three hemp varieties.

\begin{tabular}{lcc} 
Variety & Yield of seeds (kg/ha) & Yield of oil (\%) \\
\hline Santhica 27 (S27) & 1035 & 33.86 \\
Epsilon 68 (E68) & 1336 & 34.93 \\
Futura 75 (F75) & 996 & 30.45 \\
\hline
\end{tabular}

and $14.8 \%$ ) of linolenic acid (omega-3) compared with soybean oil (7.34\%), which could have favorable nutritional and physiological effects for the prevention of cardiovascular diseases and cancer [31].

The ratio of polyunsaturated acids to saturated acids for the oils studied was evaluated at $6 / 1$. This relatively high ratio would be considered favorable for reducing blood cholesterol and preventing cardiovascular disease [32]. Moreover, the results of our study indicate that the ratio of omega- 6 to omega-3 acid in hemp seeds is $3 / 1$, this results were in accordance with this reported in the literature [21,30], which is widely regarded as a ratio highly beneficial to human health [14,22].

The lipid composition obtained in the present study is also quite similar to those reported by Stambouli et al. [7] of the seeds drug-type cultivated in the north of Morocco. The weight ratios of polyunsaturated to saturated acids $(\mathrm{P} / \mathrm{S})$ and omega-6 to omega-3 fatty acids were $6: 1$ and $3: 1$, respectively.

\section{CONCLUSION}

In our study, the oil contents of the seeds were $34.93,33.86$, and $30.45 \%$ of Epsilon 68, Santhica 27, and Futura 75 varieties, respectively. The content values of linoleic, linolenic, and oleic acids were ranged between $83.6 \%$ and $87.3 \%$ of the total fatty acid composition. On the

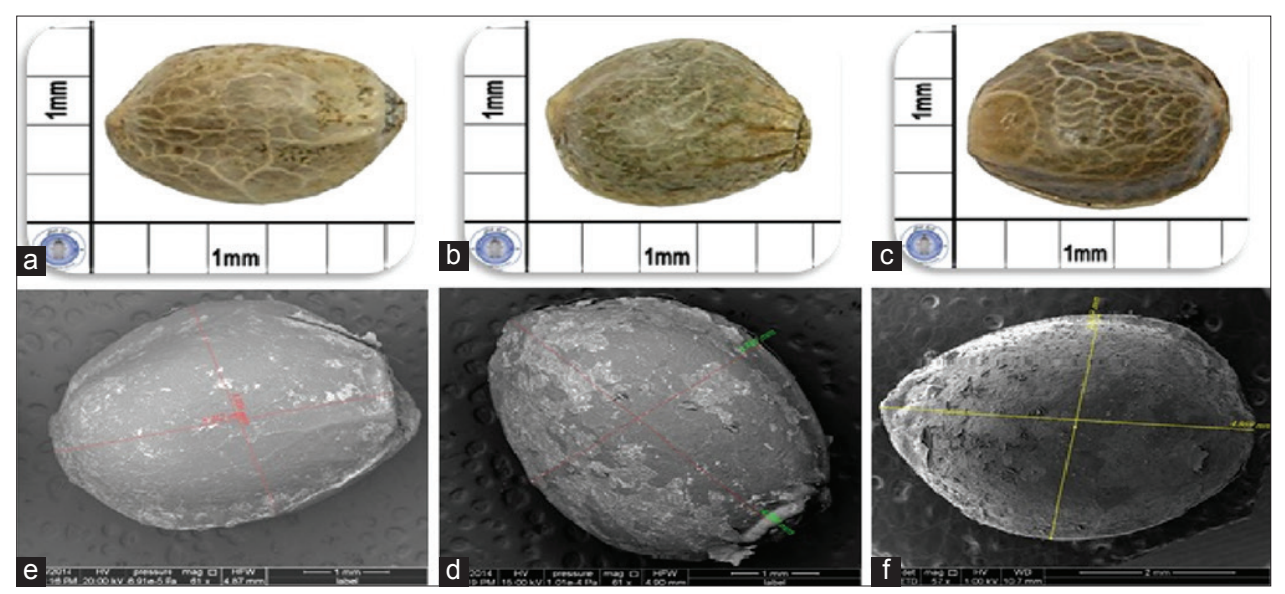

Figure 1: Microscopy of three varieties (Santhica 27, Futura 75, and Epsilon 68) of female hemp seeds cultivated in Morocco. (a) Palmitic acid (C16.0). (b) Palmitoleic acid (C16.1). (c) Stearic acid (C18.0). (d) Oleic acid (C18.1). (e) Linoleic acid (C18.2). (f) Linolenic acid (C18.3). (g) Arachidic acid (C20.0). (h) Arachidonic acid (C20.1).

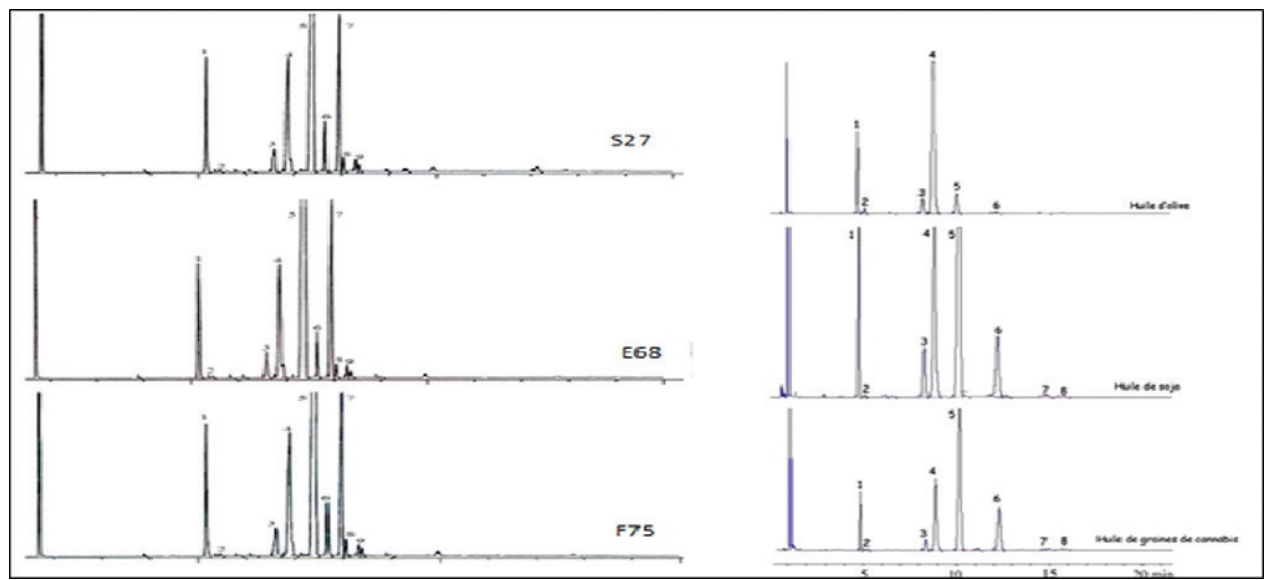

Figure 2: Gas chromatography/flame ionization detector chromatographic profile of methyl esters of vegetable oils extracted from olive, soya, and seeds of Cannabis sativa. 
Table 3: Content of fatty acid composition (\% of total oils) of hemp seed oils from three varieties of hemp (Santhica27, Epsilon 68, and Futura75) cultivated in Morocco.

\begin{tabular}{lccccccccc} 
Hemp variety & \multicolumn{7}{c}{ *Fatty acid composition (\%) } \\
\cline { 2 - 9 } & $\mathbf{C 1 6 : 0}$ & $\mathbf{C 1 6 : 1}$ & $\mathbf{C 1 8 : 0}$ & $\mathbf{C 1 8 : 1}$ & $\mathbf{C 1 8 : 2}$ & $\mathbf{C 1 8 : 3}$ (trans) & C18:3 & C20:0 & C20:1 \\
Santhica 27 & $7.70 \pm 0.03$ & $0.20 \pm 0.01$ & $2.44 \pm 0.04$ & $13.30 \pm 0.03$ & $56.71 \pm 0.1$ & $3.10 \pm 0.05$ & $13.66 \pm 0.04$ & $0.92 \pm 0.05$ & $0.82 \pm 0.02$ \\
Epsilon 68 & $7.40 \pm 0.04$ & $0.20 \pm 0.01$ & $2.60 \pm 0.04$ & $13.13 \pm 0.03$ & $57.12 \pm 0.1$ & $2.74 \pm 0.05$ & $14.80 \pm 0.06$ & $0.90 \pm 0.05$ & $0.70 \pm 0.02$ \\
Futura 75 & $7.32 \pm 0.02$ & $0.20 \pm 0.01$ & $2.40 \pm 0.02$ & $12.80 \pm 0.04$ & $57.70 \pm 0.1$ & $2.80 \pm 0.04$ & $14.72 \pm 0.03$ & $0.92 \pm 0.05$ & $0.84 \pm 0.02$ \\
\hline
\end{tabular}

*Palmitic acid (C16.0); Palmitoleic acid (C16.1); Stearic acid (C18.0); Oleic acid (C18.1); Linoleic acid (C18.2); Linolenic acid (C18.3); Arachidic acid (C20.0); Arachidonic acid (C20.1).

Table 4: Content (\% of total oils) of fatty acid composition of hemp seed oils of hemp (Santhica 27, Epsilon 68, and Futura 75) in comparison with olive and soybean oils cultivated in Morocco.

\begin{tabular}{|c|c|c|c|c|c|c|c|}
\hline \multirow[t]{2}{*}{ Fatty acid } & \multicolumn{3}{|c|}{ Hemp seeds oil (\%) } & \multicolumn{2}{|c|}{ Olive oil (\%) } & \multicolumn{2}{|r|}{ Soya oil (\%) } \\
\hline & S27 & E68 & F75 & Experiment & Standard (Fournier, 2003) & Experiment & Standard (Fournier, 2003) \\
\hline Palmitic acid (C16:0) & 7.7 & 7.4 & 7.3 & 10.11 & $(7.5-20.0)$ & 10.93 & $(8.0-13.5)$ \\
\hline Stearic acid (C18:0) & 2.4 & 2.6 & 2.4 & 3.73 & $(0.5-5.0)$ & 4.64 & $(2.0-5.4)$ \\
\hline Oleic acid (C18:1) & 13.3 & 13.1 & 12.8 & 78.66 & $(55.0-83.0)$ & 22.21 & $(17.0-30.0)$ \\
\hline $\begin{array}{l}\text { Linolenic acid (C18:3) } \\
\text { (Oméga-3) }\end{array}$ & 13.6 & 14.8 & 14.7 & 0.67 & $(\mathrm{ND}-1.0)$ & 7.34 & $(4.5-11.0)$ \\
\hline Arachidic acid (C20:0) & 0.9 & 0.9 & 0.9 & 0.40 & $(\mathrm{ND}-0.6)$ & 0.36 & $(0.1-0.6)$ \\
\hline Arachidonic acid (C20:1) & 0.8 & 0.7 & 0.8 & ND & $(\mathrm{ND}-0.4)$ & 0.18 & $(\mathrm{ND}-0.5)$ \\
\hline
\end{tabular}

ND: Not determined.

other hand, saturated fatty acids such as palmitic, stearic, and arachidic acids ranged from $7.32 \% \pm 0.02 \%$ to $7.70 \% \pm 0.03 \%, 2.40 \% \pm 0.02 \%$ to $2.60 \% \pm 0.04 \%$, and $0.9 \%$, respectively. Moreover, the results of our study indicate that the ratio of omega- 6 to omega- 3 acid in hemp seeds is $3: 1$. The results of this study showed that hemp seeds cultivated in Morocco could be used as a source of food characterized by high nutritional value.

\section{REFERENCES}

1. Afsahi K. Are Moroccan cannabis growers able to adapt to recent European market trend. Int J Drug Policy 2015;26:327-9.

2. Chouvy PA, Laniel L. Production agricole de drogues illicites et conflictualités intra-étatiques: Dimensions économiques et stratégiques. Les Cah Sécur 2006;62:223-53.

3. Chouvy PA. Morocco said to produce nearly half of the world's hashish supply. Jane's Intell Rev 2005;17:32-5.

4. United Nations Office on Drugs and Crime (UNODC). World Drug Report. New York: United Nations; 2016. Available from: http:// www.unodc.org/doc/wdr2016/WORLD_DRUGREPORT2016.

5. Stambouli H, El Bouri A, Bellimam MA, Bouayoun T, El Karni N. Concentrations du $\Delta^{9}$-THC dans les cultures de Cannabis sativa $\mathrm{L}$. du nord du Maroc. Ann Toxicol Anal 2005;17:79-86.

6. Stambouli H, El Bouri A, Bellimam MA, Bouayoun T, El Karni N. Cultivation of Cannabis sativa L. in northern Morocco. Bull Nar 2005;57:79-118.

7. Stambouli H, El Bouri A, Bellimam MA, Bouayoun T. Caractérisation de l'huile de graines de Cannabis sativa L. cultivé au nord du Maroc. Ann Toxicol Anal 2006;18:119-25.

8. Bouayoun T, Stambouli H, El Bouri A, Farah A, Saidi S, Ez Zoubi Y, et al. Comparative study of three varieties of Cannabis sativa $\mathrm{L}$. cultivate in different region of Morocco. Int J Pharmacogn Phytochem Res 2017;9:643-53.
9. Elma MJ, Zhang Q, Amaducci S, Yang M, Trindade LM. New developments in fiber hemp (Cannabis sativa L.) breeding. Ind Crops Prod 2015;68:32-41.

10. Wirtshafter DE. Ten years of a modern hemp industry. J Ind Hemp 2004;9:9-14.

11. Deferne JL, Pate DW. Hempseed oil: A source of valuable essential fatty acids. J Int Hemp Assoc 1996;3:1-4.

12. Rausch P. Verwendung von hanfsameno in der kosmetik. In: Bioresource Hemp. $2^{\text {nd }}$ ed. Cologne, Germany: Nova-Institute; 1995. p. 556-61.

13. Yu L, Zhou KK, Parry J. Antioxidant properties of cold-pressed black caraway, carrot, cranberry, and hemp seed oils. Food Chem 2005;91:723-9.

14. Da Porto C, Decorti D, Tubaro F. Fatty acid composition and oxidation stability of hemp (Cannabis sativa L.) seed oil extracted by supercritical carbon dioxide. Ind Crops Prod 2012;36:401-4.

15. Schwab US, Callaway JC, Erkkila AT, Gynther J, Uusitupa MI, Javinen T. Effects of hempseed and flaxseed oils on the profile of serum lipids, serum total and lipoprotein lipid concentrations and haemostatic factors. Eu J Nutr 2006;45:470-7.

16. Kaul N, Kreml R, Austria JA, Richard MN, Edel AL, Dibrov E, et al. A comparison of fish oil, flaxseed oil and hempseed oil supplementation on selected parameters of cardiovascular health in healthy volunteers. J Am Coll Nutr 2008;27:51-8.

17. Li Y, Yang R, Hu X, Long Z. Initial study of hemp seeds protein on antifatigue and the immunomodulation effects in mice. Wei Sheng Yan Jiu 2008;37:175-8.

18. Callaway J, Schwab U, Harvima I, Halonen P, Mykkanen O, Hyvonen $\mathrm{P}$, et al. Efficacy of dietary hempseed oil in patients with atopic dermatitis. J Derm Treat 2005;16:87-94.

19. Callaway JC. Hempseed as a nutritional resource: An overview. Euphytica 2004;140:65-72.

20. Kriese U, Schumann E, Weber WE, Beyer M, Brühl L, Matthäus B. Oil 
content, tocopherol composition and fatty acid patterns of the seeds of 51 Cannabis sativa L. genotypes. Euphytica 2004;137:339-51.

21. Oomah BD, Busson M, Godfrey DV, Drover JC. Characteristics of hemp (Cannabis sativa L.) seed oil. Food Chem 2002;76:33-43.

22. Anwar F, Latif S, Ashraf M. Analytical characterization of hemp (Cannabis sativa) seed oil from different agro-ecological zones of Pakistan. J Am Oil Chem Soc 2006;84:323-9.

23. Ozdemir O. Azot ve Bitki Sıklığının Kenevirin (Cannabis sativa L.) Verim ve Bazı Özelliklerine Etkisi. Köy Hizmetleri Araştırma Enstitüsü Müdürlüğü No: 78, Samsun; 1993.

24. Ross SA, Elsohly HN, Kashoury EA, El Sohly M. Fatty acids of cannabis seeds. Phytochem Anal 1996;7:279-83.

25. Kiralan M, Gül V, Kara ŞM. Fatty acid composition of hempseed oils from different locations in Turkey. Spanish J Agric Res 2010;8:385-90.

26. Parker TD, Adams DA, Zhou K, Haris M, Yu L. Fatty acid composition and oxidative stability of cold-pressed edible seed oils. J Food Sci 2003;68:1240-3.

27. Grundy SM. Influence of stearic acid on cholesterol metabolism relative to other long-chain fatty acids. Am J Clin Nutr 1994;60:986-90.
28. Mensink RP. Effects of stearic acid on plasma lipid and lipoproteins in humans. Lipids 2005;40:1201-5.

29. Fernández-Moya V, Martínez-Foce E, Garcés R. Oils from improved high stearic acid sunflower. Agric Food Chem 2005;53:5326-30.

30. Da Porto C, Decorti D, Natolino A. Potential oil yield, fatty acid composition, and oxidation stability of the hempseed oil from four Cannabis sativa L. cultivars. J Dietary Suppl 2015;12:1-10.

31. Oomah BD, Mazza G. Flaxseed products for disease prevention. In: Mazza G, editor. Functional Foods Biochemical and Prossing Aspects. Lancaster: Technomic Publishing Co.; 1998. p. 91-138.

32. Rudel LL, Kelly K, Sawyer JK, Shah R, Wilso MD. Dietary monounsaturated fatty acids promote aorti atherosclerosis in LDL receptor-null ApoB100-over expressing transgenic mice. Arterioscler Thromb Vasc Biol 1998;18:1818-27.

How to cite this article:
Bouayoun T, Stambouli H, Ez zoubi Y, El Bouri A, Farah A,
Tabyaoui M. Hemp seed oil: Chemical characterization of three
non-drug varieties cultivated in Morocco. J App Biol Biotech.
2018;6(05):37-41. DOI: 10.7324/JABB.2018.60506

